\title{
Portopulmonary Hypertension in Patients Undergoing Liver Transplantation: A Case Report
}

\author{
Emica Shimozono, Cristina A. A. Caruy, Adilson R. Cardoso, Ilka F. S. F. Boin \\ State University of Campinas, UNICAMP, Liver Transplant Unit of Clinics Hospital, Campinas, Brazil \\ Email: emicashi@hotmail.com
}

Received December 27, 2013; revised January 19, 2014; accepted January 25, 2014

Copyright (C) 2014 Emica Shimozono et al. This is an open access article distributed under the Creative Commons Attribution License, which permits unrestricted use, distribution, and reproduction in any medium, provided the original work is properly cited. In accordance of the Creative Commons Attribution License all Copyrights (C) 2014 are reserved for SCIRP and the owner of the intellectual property Emica Shimozono et al. All Copyright (c) 2014 are guarded by law and by SCIRP as a guardian.

\begin{abstract}
Portopulmonary hypertension (PPH) is a form of pulmonary arterial hypertension, characterized by elevation of pulmonary arterial pressure due to increased resistance to pulmonary blood flow. It is a consequence of portal hypertension, associated or not with liver disease. A retrospective study of patients undergoing liver transplantation was carried out in the Liver Transplantation Unit of the Clinics Hospital of the State University of Campinas (UNICAMP) from 1991 to 2012, covering 389 transplants. Although 50 (12.9\%) patients presented with mean pulmonary arterial pressure (MPAP) $>25 \mathrm{mmHg}$, only one case $(0.25 \%)$ met the diagnostic criteria for PPH: a 43-year-old female patient with advanced liver disease, caused by primary biliary cirrhosis with portal hypertension, diagnosed as mild portopulmonary hypertension and diagnosed in the operating room. PPH is a serious complication of portal hypertension. It is related to the great difficulty in diagnosis and the high mortality rate due to right heart failure. PPH is an entity with a low frequency of occurrence in individuals undergoing liver transplantation, although there is a wide variation in the prevalence rate presented in the literature and the definitive diagnosis should be confirmed with right heart catheterization.
\end{abstract}

\section{KEYWORDS}

\section{Portopulmonary Hypertension; Portal Hypertension; Survival; Liver Transplantation}

\section{Introduction}

The combination of pulmonary arterial hypertension with portal hypertension was initially reported in 1951 by Mantz and Craige, in a 53-year-old female patient, who had portal axis thrombosis with spontaneous portocaval shunt. The autopsy report showed that the patient had alteration in the pulmonary artery vasculature bed and a reduction in portal vein caliber $[1,2]$.

This association was termed portopulmonary hypertension (PPH) in 1993 [2,3]. It has been classified as subgroup I in the classification of pulmonary hypertension in International Symposiums on Pulmonary Hypertension in 2003, Venice and in 2008, Dana Point [4].

The various forms of pulmonary arterial hypertension were grouped into Group I according to similarity to idiopathic pulmonary arterial hypertension in terms of histopathological, pathophysiological and therapeutic characteristics, characterized by lesions in the small distal pulmonary arteries ( $<500 \mu \mathrm{m}$ in diameter), described as hypertrophy of the mean muscle layer, intimal proliferation that may appear as concentric or eccentric intimal fibrosis, thickening of the adventitia with moderate perivascular inflammatory infiltrates, formation of plexiform lesions and in situ thrombi. This results in progressive obstruction to pulmonary arterial flow from the right ventricle to the lungs, increased pulmonary arterial pressure and increased pulmonary vascular resistance [4].

The diagnosis of PPH is based on hemodynamic criteria, obtained by right heart catheterization: mean pulmonary arterial pressure (MPAP) $>25 \mathrm{mmHg}$, pulmonary vascular resistance $(\mathrm{PVR})>240$ dynes $\cdot \mathrm{s} \cdot \mathrm{cm}^{-5}$, and normal pulmonary artery occlusion pressure (PAOP) $<15$ $\mathrm{mmHg}$ or transpulmonary pressure gradient (TPG) $>10$ $\mathrm{mmHg}$, the latter useful for differentiating status of volume overload where TPG $<10 \mathrm{mmHg}$. Diagnostic criteria were proposed by the European Respiratory Society- 
European Association for the Study of the Liver (ERSEASL) Task Force on Pulmonary-Hepatic Vascular Disorders (PHD), 2004 [5].

A classification of severity of $\mathrm{PPH}$ was proposed and based on MPAP: mild (25 to $34 \mathrm{mmHg}$ ); moderate (35 to $44 \mathrm{mmHg})$ and severe $(\geq 45 \mathrm{mmHg})[5,6]$. A moderate increase in MPAP may be found in more than $20 \%$ of patients with cirrhosis, due to increased cardiac output (CO) and/or volume overload, despite lack of pulmonary vascular remodeling [5,7].

Data from prospective hemodynamic studies revealed that $2 \%$ to $6 \%$ of patients with portal hypertension develop $\mathrm{PPH}$ [8]. The prevalence in patients undergoing liver transplantation is quite conflicting, ranging from 3.5\% to $8.5 \%$, and some authors report more than $10 \%$ [9]. More recent studies using criteria from the current guidelines [5] have reported a prevalence rate of 5.3\% (Krowka et al.) [10] and 4.6\% (Raevens et al.) [11].

\section{Case Presentation}

Of 585 patients undergoing liver transplantation, 389 were analyzed from 1991 to 2012 at the UNICAMP Clinics Hospital. Inclusion criteria were: aged over 18 years, regardless of race or gender, with advanced liver disease and portal hypertension (diagnosis by abdominal ultrasound and upper digestive endoscopy). Exclusion criteria were: double graft, fulminant hepatitis, retransplant, hepatopulmonary syndrome, MPAP > $50 \mathrm{mmHg}$, with 2 cases diagnosed in the operating room after induction of anesthesia and patients with incomplete data. Of the 389 patients, 50 (12.9\%) had MPAP > $25 \mathrm{mmHg}$, but only one patient $(0.25 \%)$ met the diagnostic criteria in the current guidelines [5].

All patients received general anesthesia and orotracheal intubation (OTI), then underwent invasive monitoring by bilateral radial artery catheterization, right heart catheterization (RHC) with Swan-Ganz catheter (Edwards Lifesciences, Irvine California, USA), measuring the following hemodynamic data [12]: mean arterial pressure (MAP) (normal range $=77-97 \mathrm{mmHg}$ ), central venous pressure (CVP) (normal range $=4-8 \mathrm{mmHg}$ ), MPAP (normal range $=10-20 \mathrm{mmHg}$ ), PAOP (normal range $=5-15 \mathrm{mmHg}$ ), $\mathrm{CO}$ (normal range $=4-6 \mathrm{l} / \mathrm{min}$ ) (by thermodilution, 3 saline injections), PVR (normal range $=50-150$ dynes $\cdot \mathrm{s}^{\cdot} \mathrm{cm}^{-5}$ ), and TGP calculated by the formula:

$$
\mathrm{PVR}=\frac{\mathrm{MPAP}-\mathrm{PAOP}}{\mathrm{CO}} \times 80
$$

TPG $=$ MPAP - PAOP.

Mild PPH (MPAP between 25 and $34 \mathrm{mmHg}$ ) was diagnosed in a 43-year-old female patient with advanced stage liver disease and portal hypertension caused by primary biliary cirrhosis.
On pretransplant evaluation, the patient had normal transthoracic Doppler echocardiography (performed 6 months before liver transplantation); normal chest radiography and electrocardiogram (EKG); pulmonary function test (PFT) with mild obstructive pattern; ALT $=66$ $\mathrm{UI} / \mathrm{L} ; \mathrm{AST}=118 \mathrm{UI} / \mathrm{L} ; \mathrm{GGT}=449 \mathrm{UI} / \mathrm{l} ; \mathrm{AP}=3079 \mathrm{UI} / \mathrm{l}$; $\mathrm{TB}=22.9 \mathrm{mg} / \mathrm{dl}$; albumin $=2.9 \mathrm{mg} / \mathrm{dl}, \mathrm{INR}=1.31$, urea $=24 \mathrm{mg} / \mathrm{dl}$; creatinine $=0.36 \mathrm{mg} / \mathrm{dl}$; blood gas analysis: $\mathrm{pH}=7,43 ; \mathrm{pO}_{2}=84,5 \mathrm{mmHg} ; \mathrm{pCO}_{2}=30 \mathrm{mmHg} ; \mathrm{BE}=$ -2.2; $\mathrm{SatO}_{2}=96 \%$; CTP score (Child-Turcotte-Pugh): class C (10 points) and MELD (Model End-Stage for Liver Disease) $=21$ points.

The patient underwent liver transplantation (LT) using the piggy back technique.

The following hemodynamic data were present after induction of anesthesia: $\mathrm{MAP}=80 \mathrm{mmHg}, \mathrm{CVP}=3$ $\mathrm{mmHg}$, MPAP = $31 \mathrm{mmHg}$, PAOP = $11 \mathrm{mmHg}, \mathrm{CO}=$ $2.3 \mathrm{l} / \mathrm{min}, \mathrm{PVR}=696 \mathrm{dynes} \cdot \mathrm{s} \cdot \mathrm{cm}^{-5}, \mathrm{TPG}=20 \mathrm{mmHg}$, characterizing mild $\mathrm{PPH}$.

The duration of cold ischemia was 990 minutes, warm ischemia was 165 minutes and surgery lasted $660 \mathrm{mi}-$ nutes. The patient received 27 units of packed red blood cells, 20 units of fresh frozen plasma, 20 units of platelet concentrates, 4 units of human albumin in the intraoperative period. In the intraoperative period, complication was arterial hypotension, requiring noradrenalin and dopamine.

In the postoperative period, she presented with primary graft failure. Alanine aminotransferase (ALT) level was $22,700 \mathrm{UI} / \mathrm{L}$. The patient was not extubated and died on the second postoperative day.

\section{Discussion}

Portopulmonary hypertension is a condition characterized by increased pulmonary arterial pressure due to increased resistance to pulmonary blood flow in the setting of portal hypertension [10].

$\mathrm{PPH}$ affects adults and the mean patient age is 47 years (ranging from 30 to 60 years). It affects men and women [13]. A study by Kawut et al., showed a correlation with female sex, autoimmune hepatitis, without relation to hepatitis C virus and disease severity [14]. In our case, the patient was a 43-year old adult, presenting with biliary cirrhosis, unrelated to autoimmune hepatitis but related to CTP C score, and MELD 21 score, therefore related to the severity of disease.

Studies have demonstrated that increased MPAP may be found in more than $20 \%$ of patients with cirrhosis, or advanced liver disease, without increased pulmonary vascular resistance, due to an increased CO and/or volume overload $[5,10]$. In our study, $12.9 \%(n=50)$ of the 389 patients undergoing LT had the such conditions: median (minimum-maximum), MAP = 80 (50 - 110) mmHg; CVP = 13 (5 - 36) mmHg; MPAP = 28 (26 - 44) mmHg; 
PAOP = 19 (4 - 29) mmHg; CO = 9 (2.1 - 16) l/min; PVR = 96 (33 - 696) dynes $\cdot \mathrm{s} \cdot \mathrm{cm}^{-5}$; GTP = 10 (4 - 22) $\mathrm{mmHg}$.

The MPAP may be increased without pulmonary vascular remodeling in the following conditions: 1) Hyperdinamic circulatory state, the high flow circulatory is a consequence of splanchnic vasodilation caused by portal hypertension that results in high cardiac output, increased MPAP and decreased or normal pulmonary vascular resistance [10]. 2) An excess central volume associated with systolic dysfunction or diastolic dysfunction or renal insufficiency, measured by high pulmonary artery occlusion pressure [4].

Regarding analysis of the pretransplant tests, there was no correlation between the findings obtained, chest radiography, electrocardiogram, pulmonary function test and existence of $\mathrm{PPH}$. In patients with end stage liver disease the abnormalities found on chest radiography are usually due to volume overload. Sensitivity for findings such as right ventricular hypertrophy on EKG ranges from $25 \%$ to $40 \%[15,16]$. Pilatis et al. correlated an abnormal result in PFT with the presence of ascites, without specific alterations for PPH [16]. Arterial blood gas analysis may show mild to moderate hypoxemia with decreased $\mathrm{paCO}_{2}[5,17]$ resulting in compensatory respiratory alkalosis, as shown by hypocapnea in the case report.

Transthoracic Doppler echocardiography is the noninvasive modality used for screening $\mathrm{PPH}$. It is related to a sensitivity of $100 \%$, specificity of $96 \%$, positive predictive value of $59 \%$ and negative predictive value of $100 \%$ (for a cutoff value of right ventricular systolic pressure > $30 \mathrm{mmHg}$, compared to RHC), according to Colle et al. [18]. In our case, the patient had a normal result, which may have been related to the time in which the test was performed, absence of tricuspid regurgitation and operator experience. Previous studies showed that $\mathrm{PPH}$ is progressive and may develop within a short time (two to three months) [11].

Right heart catheterization is the gold standard for the diagnosis of $\mathrm{PPH}$, allowing for the measurement of pressure, flow, volume and resistance $[4,5,10]$. Our patient was diagnosed with $\mathrm{PPH}$ in the operating room. It is recommended that the diagnosis should be made before liver transplantation, to initiate pulmonary vasodilator therapy before LT and achieve MPAP $<35 \mathrm{mmHg}$, resulting in lower patient morbidity and mortality $[6,18]$.

The mortality rate after liver transplantation is $50 \%$, if MPAP > $35 \mathrm{mmHg}$ and 100\% if MPAP $\geq 50 \mathrm{mmHg}$ due to cardiopulmonary complications [6].

Although this was a case of mild PPH (MPAP $=31$ $\mathrm{mmHg}$ ), a pressure level that is not correlated with cardiopulmonary complication and death $[19,20]$, the outcome was poor. There was massive bleeding in the intraoperative period, massive transfusion, primary graft fail- ure, $\mathrm{ALT}=22,700 \mathrm{UI} / \mathrm{L}$ and the patient died on the second postoperative day. According to the literature, massive transfusion increases the mortality risk, since the risk of mortality per unit of red blood cells transfused increases 6\%, and for each $1000 \mathrm{UI} / \mathrm{L}$ of ALT the risk of mortality increases $24 \%$ [21].

\section{Conclusion}

Portopulmonary hypertension is a rare and severe complication of cirrhosis accompanied by portal hypertension, associated or not with liver disease. In the literature, data on the prevalence of this disorder in patients undergoing liver transplantation are quite conflicting due to the different diagnostic criteria for PPH used by authors.

\section{REFERENCES}

[1] F. A. Mantz and E. Craige, "Portal Axis Thrombosis with Spontaneous Portocaval Shunt and Resultant cor Pulmonale,” Archives of Pathology, Vol. 52, No. 1, 1951, pp. 91-97.

[2] P. Hervé, D. Liberec, F. Brenot, G. Simonneau, O. Sitbon and P. Duroux, "Pulmonary Vascular Disorders in Portal Hypertension,” European Respiratory Journal, Vol. 11, No. 5, 1998, pp. 1153-1166. http://dx.doi.org/10.1183/09031936.98.11051153

[3] L. J. Rubin, "Primary Pulmonary Hypertension ACCP Consensus Statement,” Chest, Vol. 104, No. 1, 1993, pp. 236-250. http://dx.doi.org/10.1378/chest.104.1.236

[4] N. Galiè, M. M. Hoeper, M. Humbert, et al., "ESC Committee for Practice Guidelines. Guidelines for the Diagnosis and Treatment of Pulmonary Hypertension: The Task Force for the Diagnosis and Treatment of Pulmonary Hypertension of the European Society of Cardiology (ESC) and the European Respiratory Society (ERS), Endorsed by the International Society of Heart and Lung Transplantation (ISHLT)," European Heart Journal, Vol. 30, No. 20, 2009, pp. 2493-2537.

http://dx.doi.org/10.1093/eurheartj/ehp297

[5] R. Rodriguez-Roisin, M. J. Krowka, P. Hervè and M. B. Fallon, "Pulmonary-Hepatic Vascular Disorders: A Task Force Report,” European Respiratory Journal, Vol. 24, No. 5, 2004, pp. 861-880. http://dx.doi.org/10.1183/09031936.04.00010904

[6] Z. Safdar, S. Bartolome and N. Sussman, "Portopulmonary Hypertension: An Update,” Liver Transplantation, Vol. 18, No. 8, 2012, pp. 881-891. http://dx.doi.org/10.1002/lt.23485

[7] S. Giusca, M. Jinga, J. Ciprian, et al., "Portopulmonary Hypertension: From Diagnosis to Treatment," European Journal of Internal Medicine, Vol. 22, No. 5, 2011, pp. 441-447. http://dx.doi.org/10.1016/j.ejim.2011.02.018

[8] M. Castro, M. J. Krowka, D. R. Schroeder, et al., "Frequency and Clinical Implications of Increased Pulmonary Artery Pressures in Liver Transplant Patients," Mayo Clinic Proceedings, Vol. 71, No. 6, 1996, pp. 543-551. http://dx.doi.org/10.4065/71.6.543 
[9] P. C. Kuo, J. S. Plotkin, S. Gaine, R. A. Schroeder, V. K. Rustgi, L. J. Rubin and L. B. Johnson, "Portopulmonary Hypertension and the Liver Transplantation Candidate," Transplantation, Vol. 67, No. 8, 1999, pp. 1087-1093.

[10] M. J. Krowka, R. P. Swanson, M. D. MacGoon and R. H. Wiesner, "Portopulmonary Hypertension: Results from a 10-Year Screening Algorithm,” Hepatology, Vol. 44, No. 6, 2006, pp. 1502-1510. http://dx.doi.org/10.1002/hep.21431

[11] S. Raevens, I. Colle, K. Reyntjens, et al., "Echocardiography for the Detection of Portopulmonary Hypertension in Liver Transplant Candidates: An Analysis of Cutoff Values," Liver transplantation, Vol. 19, No. 6, 2013, pp. 602-610. http://dx.doi.org/10.1002/lt.23649

[12] A. Silva, “Anesthesia Monitoring," In: R. D. Miller and M. C. Pardo Jr., Eds., Basics of Anesthesia, 6th Edition, Elsevier, Rio de Janeiro, 2012.

[13] S. M. Mandell and B. M. Groves, "Pulmonary Hypertension in Chronic Liver Disease," Clinics in Chest Medicine, Vol. 17, No. 1, 1996, pp. 17-33. http://dx.doi.org/10.1016/S0272-5231(05)70296-3

[14] S. M. Kawut, M. J. Krowka, J. F. Trotter, et al., "Clinical Risk Factors for Portopulmonary Hypertension,” Hepatology, Vol. 48, No. 1, 2008, pp. 196-203. http://dx.doi.org/10.1002/hep.22275

[15] B. Surawitz, "Eletrocardiographic Diagnosis of Chamber Enlargement," Journal of the American College of Cardiology, Vol. 8, No. 3, 1986, pp. 711-724. http://dx.doi.org/10.1016/S0735-1097(86)80207-8

[16] N. D. Pilatis, L. E. Jacobs, P. Rerkpattanapipat, N. K. Morris, A. Owen, C. Manzarbeitia, D. Reich, K. Rothstein and S. J. Munoz, "Clinical Predictors of Pulmonary
Hypertension in Patients Undergoing Liver Transplant Evaluation,” Liver Transplantation, Vol. 6, No. 1, 2000, pp. 85-91.

[17] J. M. Golbin and M. J. Krowka, "Portopulmonary Hypertension,” Clinics in Chest Medicine, Vol. 28, No. 1, 2007, pp. 203-218. http://dx.doi.org/10.1016/j.ccm.2006.11.004

[18] I. O. Colle, R. Moreau, E. Godinho, et al., "Diagnosis of Portopulmonary Hypertension in Candidates for Liver Transplantation: A Prospective Study,” Hepatology, Vol. 37, No. 2, 2003, pp. 401-409. http://dx.doi.org/10.1053/jhep.2003.50060

[19] K. L. Swanson, R. H. Wiesner, S. L. Nyberg, C. B. Rosen and M. J. Krowka, "Survival in Portopulmonary Hypertension: Mayo Clinic Experience Categorized by Treatment Subgroups," American Journal of Transplantation, Vol. 8, No. 11, 2008, pp. 2445-2453. http://dx.doi.org/10.1111/j.1600-6143.2008.02384.x

[20] M. J. Krowka, D. J. Plevak, J. Y. Findlay, C. B. Rosen, R. H. Wiesner and R. A. F. Krom, "Pulmonary Hemodynamics and Perioperative Cardiopulmonary-Related Mortality in Patients with Portopulmonary Hypertension Undergoing Liver Transplantation,” Liver Transplantation, Vol. 6, No. 4, 2000, pp. 443-450.

[21] I. F. S. F. Boin, M. I. Leonardi, E. Y. Udo, T. Sevá-Pereira, R. B. Stucchi and L. S. Leonardi, "Aplicação do Escore MELD em Pacientes Submetidos a Transplante de Fígado: Análise Retrospectiva da Sobrevida e dos Fatores Preditivos a Curto e Longo Prazo," Arquivos de Gastroenterologia, Vol. 45, No. 4, 2008, pp. 275-283. http://dx.doi.org/10.1590/S0004-28032008000400004 